\title{
Sensitivity of Polar Amplification to Varying Insolation Conditions $\mathscr{0}$
}

\author{
DOYEON KiM, SARAH M. KANG, AND YeCHUl SHIN \\ School of Urban and Environmental Engineering, Ulsan National Institute of Science and Technology, Ulsan, South Korea \\ NICOLE FELDL \\ Department of Earth and Planetary Sciences, University of California, Santa Cruz, Santa Cruz, California
}

(Manuscript received 21 September 2017, in final form 28 March 2018)

\begin{abstract}
The mechanism of polar amplification in the absence of surface albedo feedback is investigated using an atmospheric model coupled to an aquaplanet slab ocean forced by a $\mathrm{CO}_{2}$ doubling. In particular, we examine the sensitivity of polar surface warming response under different insolation conditions from equinox (EQN) to annual mean (ANN) to seasonally varying (SEA). Varying insolation greatly affects the climatological static stability. The equinox condition, with the largest polar static stability, exhibits a bottom-heavy vertical profile of polar warming response that leads to the strongest polar amplification. In contrast, the polar warming response in ANN and SEA exhibits a maximum in the midtroposphere, which leads to only weak polar amplification. The midtropospheric warming maximum, which results from an increased poleward atmospheric energy transport in response to the tropics-to-pole energy imbalance, contributes to polar surface warming via downward clear-sky longwave radiation. However, it is cancelled by negative cloud radiative feedbacks locally. Furthermore, the polar lapse rate feedback, calculated from radiative kernels, is negative due to the midtropospheric warming maximum, and hence is not able to promote the polar surface warming. On the other hand, the polar lapse rate feedback in EQN is positive due to the bottom-heavy warming response, contributing to the strong polar surface warming. This contrast suggests that locally induced positive radiative feedbacks are necessary for strong polar amplification. Our results demonstrate how interactions among climate feedbacks determine the strength of polar amplification.
\end{abstract}

\section{Introduction}

Recently, the near-surface temperature in the polar region has been increasing at a faster rate than the global average, and this effect is called polar amplification (Arrhenius 1896; Manabe et al. 1991; Holland and Bitz 2003; Cai 2005; IPCC 2007). Models and observations robustly present a polar amplified surface warming pattern from $\mathrm{CO}_{2}$ radiative forcing (Bekryaev et al. 2010; Hwang et al. 2011).

Various feedback mechanisms within the climate system are suggested to contribute to polar amplification. Among them, the surface albedo feedback is widely accepted to play a leading role (Arrhenius 1896;

\footnotetext{
T) Supplemental information related to this paper is available at the Journals Online website: https://doi.org/10.1175/JCLI-D-170627.s1.

Corresponding author: Sarah M. Kang, skang@unist.ac.kr
}

Manabe and Wetherald 1975; Screen et al. 2012). With global warming, melting of sea ice and snow decreases the surface albedo, enhancing the absorption of solar radiation, thereby contributing to warming the polar surface. However, the polar surface warming response is amplified even in simulations with no surface albedo feedback (Alexeev et al. 2005; Langen et al. 2012). This indicates that mechanisms other than the locally induced surface albedo feedback are at play, such as changes in atmospheric energy transport (Alexeev et al. 2005; Cai 2005; Chung and Räisänen 2011), cloud feedbacks (Vavrus 2004), and lapse rate feedback (Pithan and Mauritsen 2014).

The lapse rate feedback associated with the vertical profile of atmospheric warming has been proposed to be the dominant contributor to polar amplification (Manabe and Wetherald 1975; Graversen and Wang 2009; Pithan and Mauritsen 2014). In the tropics with deep convection, the vertical temperature profile closely follows a moist adiabat, thereby producing greater 
warming in the upper troposphere than at the surface. This top-heavy warming profile is effective at radiating longwave radiation to space, so that less surface warming is needed to balance a given radiative forcing. In the polar region, moist convection is inhibited due to a large static stability. The inversion layer keeps near-surface air from being mixed with the air aloft, leading to a bottom-heavy warming profile that is ineffective at producing large outgoing longwave radiation, and hence requiring a larger surface warming to balance a given radiative forcing (Manabe and Wetherald 1975; Tjernström and Graversen 2009; Graversen and Wang 2009). Since the lapse rate feedback is negative in the tropics and positive in the polar region, it contributes to inducing the polar amplified surface warming pattern. Note, however, that the high-latitude lapse rate feedback needs to be distinguished from the tropical lapse rate feedback. The vertical temperature profile in the tropical troposphere is determined locally by a moist adiabat, whereas the static stability of high latitudes can be modulated by changes in the atmospheric energy transport due to some remote radiative forcing. This sensitivity of high-latitude lapse rate to forcing is explained in terms of a forcing-dependent lapse rate feedback (Cronin and Jansen 2016).

Other mechanisms for polar amplification include the longwave radiative feedback associated with an increase in water vapor and cloud cover (Winton 2006; Graversen and Wang 2009). Complications arise as cloud cover affects the efficacy of surface albedo feedback (Kay et al. 2012). A reduced cloud cover enhances the albedo feedback (Hofer et al. 2017), whereas the effect of changes in surface albedo in the overcast regions would be obscured by reflective clouds. Enhanced poleward heat transport by the atmosphere and/or ocean has also been identified as a factor that contributes to the polar surface warming amplification (Holland and Bitz 2003; Cai 2005; Chung and Räisänen 2011). To examine the relative contribution of each mechanism, various feedback analysis has been applied (Taylor et al. 2011a,b; Pithan and Mauritsen 2014). Also, a number of studies utilize idealized experiments with models of varying complexity from simple energy balance models or box models (Alexeev et al. 2005; Cai 2005; Merlis and Henry 2018) to comprehensive GCMs (Chung and Räisänen 2011; Graversen and Burtu 2016). However, it is still difficult to cleanly isolate processes controlling polar amplification because multiple mechanisms act locally as well as interact remotely with each other (Graversen et al. 2014).

The seasonal differences in multiple mechanisms give rise to a pronounced seasonality in the polar surface warming. Both models and observations feature the largest polar surface warming in winter and smallest in summer (Wetherald and Manabe 1981; Lu and Cai 2009; Bintanja et al. 2012; Sejas et al. 2014). This is counterintuitive as sea ice reductions and the associated ice albedo feedback are strongest in summer. Instead, it is explained by an increase in winter oceanic heat loss in response to the loss of summer ice cover (Screen and Simmonds 2010; Cohen et al. 2012). Reduced sea ice extent in summer enhances the solar absorption at the subsurface ocean (Perovich et al. 2008), which is released to the atmosphere in autumn and winter by radiative and turbulent fluxes because the air temperatures are lower than the ocean surface (Serreze et al. 2009; Inoue and Hori 2011). An alternative explanation for the amplified polar winter warming is that the surface thermal inversion during cold seasons intensifies the polar surface warming through downward longwave radiation (Bintanja et al. 2012).

The pronounced seasonality in polar amplification casts doubt on the validity of idealized studies under the annual-mean insolation. For instance, Alexeev et al. (2005) demonstrate clear polar amplification in the absence of surface albedo feedback under annual-mean insolation. However, the experiments with a seasonal cycle in Feldl et al. (2017a), where the strength of the surface albedo feedback is manipulated, suggest that surface warming is relatively uniform in the experiment with the negligible surface albedo feedback. The contrasting results raise the question of the role of the inclusion of a seasonal cycle on polar amplification. A series of seminal works by Manabe indicate that the polar amplification is less pronounced in the simulation with a seasonal cycle than the simulation with annualmean insolation because of the lack of surface albedo feedback during the summer (Wetherald and Manabe 1981; Manabe et al. 1991, 1992). In this study, we attempt to understand the disparate mechanisms of polar amplification under various insolation conditions in the absence of a surface albedo feedback.

\section{Experimental configurations}

We employ an atmospheric general circulation model, AM2 developed at the Geophysical Fluid Dynamics Laboratory (GFDL), which participated in phases 3 and 5 of the Coupled Model Intercomparison Project (CMIP3 and CMIP5) (Anderson et al. 2004). The model is run at a horizontal resolution of $2^{\circ}$ latitude $\times 2.5^{\circ}$ longitude and 24 vertical levels. The atmosphere is coupled to an aquaplanet slab ocean with a depth of $10 \mathrm{~m}$. The surface temperatures are allowed to drop below freezing temperature without forming any sea ice, thus disabling the surface albedo feedback. The 
reference integration with $348 \mathrm{ppm}$ of $\mathrm{CO}_{2}$ concentration is perturbed by a $\mathrm{CO}_{2}$ doubling. Both the reference $(1 \mathrm{xCO} 2)$ and perturbed $(2 \mathrm{xCO} 2)$ integrations are forced by different insolation conditions: perpetual equinox (denoted as EQN), annual-mean insolation (denoted as ANN), or with a seasonal cycle (denoted as SEA). In SEA, the eccentricity is set to zero so that Earth has a perfectly circular orbit with no perihelion. All experiments are run for 45 years with 20 years of spinup.

\section{a. Prescribed cloud radiative feedback}

As previous studies pointed to the important roles played by clouds, SEA and ANN are simulated with prescribed clouds in order to cleanly examine the effect of cloud adjustments on polar amplification. A randomly chosen 1-yr time series of the 3D cloud water mixing ratio, cloud ice mixing ratio, and cloud fractional area in the respective $1 \mathrm{xCO} 2$ experiment is prescribed at every $3 \mathrm{~h}$ in the radiative scheme for both $1 \mathrm{xCO} 2$ and $2 \mathrm{xCO} 2$ experiments. The prescribed cloud experiments of SEA and ANN are denoted as SEAFC and ANNFC, respectively. In addition, we perform SEA with clouds prescribed over a limited area to contrast the role of cloud radiative effect in the tropics and the polar region. The experiment with prescribed clouds over $30^{\circ} \mathrm{S}-30^{\circ} \mathrm{N}$ is denoted as SEAFC_TRO, and that with prescribed clouds poleward of $60^{\circ} \mathrm{S} / \mathrm{N}$ as SEAFC_POL. The prescribed cloud experiments are discussed in section $3 \mathrm{~b}$ and all experiments are summarized in Table $\mathrm{S} 1$ in the online supplemental material.

\section{b. Radiative kernel}

To examine the relative importance of various feedbacks, we apply the radiative kernel method of calculating climate feedbacks (Soden et al. 2008; Feldl and Roe 2013a,b). The change in TOA net radiation $(\Delta R)$ can be decomposed into climate feedbacks and forcing by a Taylor series expansion in surface temperature change $\left(\Delta T_{s}\right)$

$$
\Delta R=\sum_{i} \lambda_{i} \Delta T_{s}+\Delta R_{f}+\varepsilon .
$$

All terms in Eq. (1) are functions of latitude and month. The first term on the right-hand side represents the combined climate feedbacks where $\lambda$ is calculated from radiative kernels in Feldl et al. (2017a). It includes Planck, lapse rate, water vapor, and cloud feedbacks. The $R_{f}$ term represents the radiative forcing of a $\mathrm{CO}_{2}$ doubling. Among various radiative forcing definitions, we use the fixed-SST forcing method (Hansen et al. 2005; Feldl and Roe 2013b). For example, the $R_{f}$ term for prescribed cloud experiments (SEAFC) is calculated with the SST prescribed to the zonal-mean monthly profiles of SEAFC and clouds prescribed to their zonalmean profiles of SEA at every $3 \mathrm{~h}$ as in the prescribed cloud experiments. The residual $\varepsilon$ is higher-order terms in the Taylor series expansion, which reflect nonlinearities within individual process or nonlinear interactions among different processes. Analysis on the climate feedbacks is offered in section $3 \mathrm{~d}$.

\section{Results}

\section{a. Polar amplification in an aquaplanet}

Figure 1a compares the surface temperature response to $2 \mathrm{xCO} 2$ in EQN, ANN, and SEA. The three aquaplanet experiments with different insolation conditions exhibit vastly different global climate sensitivity, defined as the global mean surface temperature response to 2xCO2: $3.1,2.3$, and $2.5 \mathrm{~K}$ in EQN, ANN, and SEA, respectively. All experiments exhibit a lower global climate sensitivity than that in Feldl and Roe (2013a) of $4.7 \mathrm{~K}$ due to the lack of a surface albedo feedback. The higher global climate sensitivity in EQN relative to the other two experiments results from stronger polar amplification. In EQN, the surface poleward of $70^{\circ}$ is warmed by $6.1 \mathrm{~K}, 70 \%$ more than the global-mean response, whereas the contrast is only $20 \%$ in ANN. In SEA, the latitudinal profile of the surface warming response is nearly flat, indicative of no polar amplification. This stark contrast is influenced by differences in the vertical temperature profiles at high latitudes in the respective control climates due to the varying insolation condition.

The polar region in EQN exhibits a large static stability near the surface (Fig. 1b) because of the yearround near zero solar radiation reaching the polar region under equinox. The large stability in the boundary layer in EQN leads to a surface trapped warming, which is hence more amplified than in other experiments through the positive lapse rate feedback (Fig. S1). In contrast, both ANN and SEA do not exhibit any maxima in static stability near the surface in the polar region (Figs. 1c,d), leading to a slightly negative lapse rate feedback there (see Fig. S1 in the online supplemental material). For reference, Fig. S1 compares the contribution of lapse rate feedback to the surface temperature response in the three experiments. It is the distinctive insolation pattern in EQN that greatly stabilizes the polar region to induce a bottom-heavy structured warming, resulting in strong polar amplification even without any sea ice. On the other hand, the ANN and SEA experiments in the absence of surface albedo feedback exhibit a small static stability in the polar region that leads to negative lapse rate feedback. In more 
(a) $\Delta T_{s}$

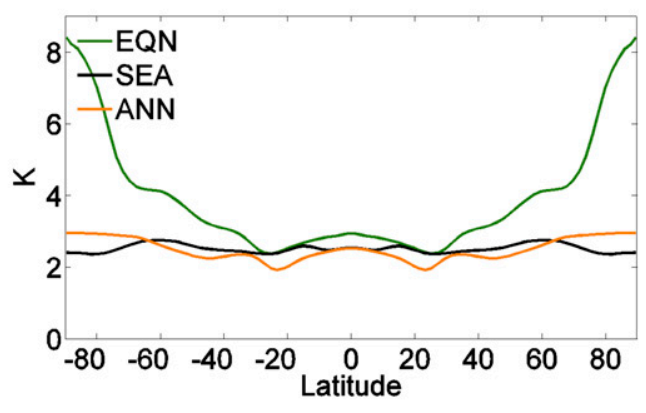

(c) ANN

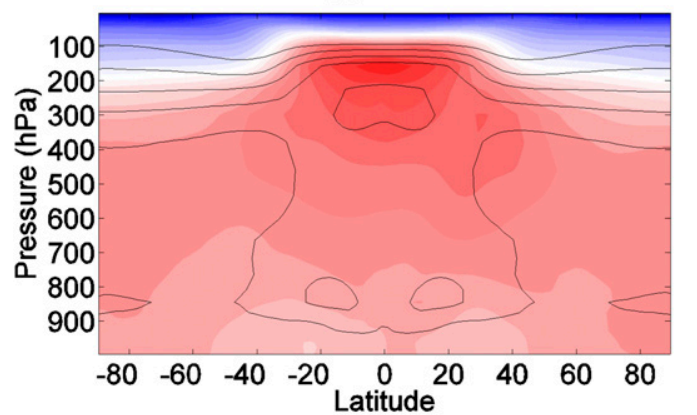

(b) EQN

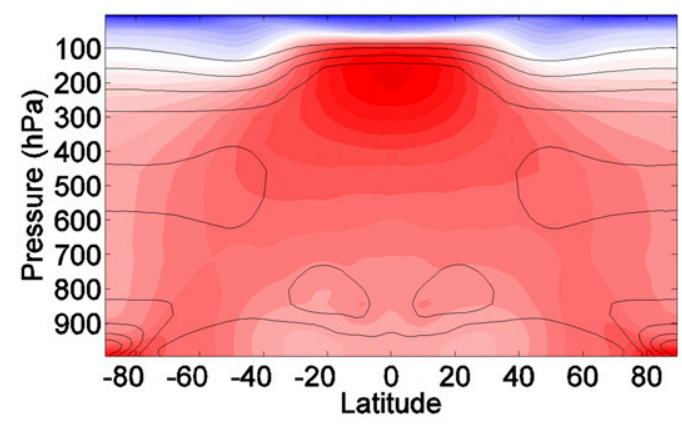

(d) SEA

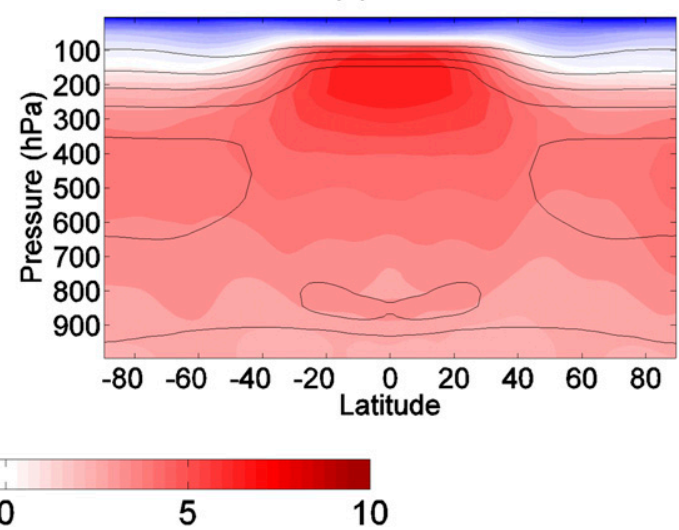

FIG. 1. (a) Zonal- and time-mean surface temperature response (K) in $2 \mathrm{xCO}_{2}$. (b)-(d) Shading indicates the zonal- and time-mean temperature response $(\mathrm{K})$ in $2 \mathrm{xCO}_{2}$ and contours indicate the static stability [with an interval of $\left.0.4^{\circ} \mathrm{C}(100 \mathrm{~m})^{-1}\right]$ in $1 \mathrm{xCO}_{2}$, defined as $d \theta / d z=-\rho g /(R T) \times d \theta / d p$ following Graversen and Wang (2009), in (b) EQN, (c) ANN, and (d) SEA.

comprehensive models with sea ice, the cold sea ice cover gives rise to a highly stable state, thereby trapping heat near the surface and enhancing the lapse rate feedback. As a result, the bottom-heavy warming profile is a common feature associated with polar amplification (Serreze et al. 2009; Screen et al. 2012).

Note that the observed inversion strength and temperature in the polar region are closer to those in EQN, rather than ANN or SEA (Pavelsky et al. 2011). Moreover, the observed polar atmospheric state resembles the EQN experiment more frequently than the ANN and SEA experiments, following the categorization of polar atmospheric regimes based on the lowertropospheric stability using satellite data in Taylor et al. (2015): the EQN experiment fits in the highly stable regime (whose frequency of occurrence is 0.36) whereas the ANN and SEA experiments fit in the stable regime (whose frequency of occurrence is 0.28 ). However, it is worth noting that EQN resembles the observed state for the wrong reason: the static stability in EQN is large due to the year-round near zero solar radiation reaching the polar region whereas sea ice is responsible for the very stable polar region in the real world.

The polar warming patterns in ANN and SEA, with a peak warming in the midtroposphere, are distinguished from those in EQN (Figs. 1b-d). In ANN and SEA, the warming response cannot be trapped near the surface, in the absence of any sea ice and surface albedo feedback, due to a weaker stability in the boundary layer compared to EQN. Even the stability in the wintertime of SEA is not large enough to trap warming near the surface. Instead, the polar warming response is peaked in the midtroposphere and is dispersed vertically, inducing a weak polar amplified warming at the surface. Previous work has suggested that the midtropospheric warming in the polar region is caused by an increase in atmospheric energy transport from lower latitudes (Graversen and Burtu 2016; Screen et al. 2012). This assertion is supported by our result (Fig. 2a) that shows a high correlation of 0.67 between the anomalous total atmospheric energy transport (AET) at $70^{\circ}$ and the midtropospheric warming magnitude averaged poleward of $70^{\circ}$. Note that the total AET is calculated 
(a)

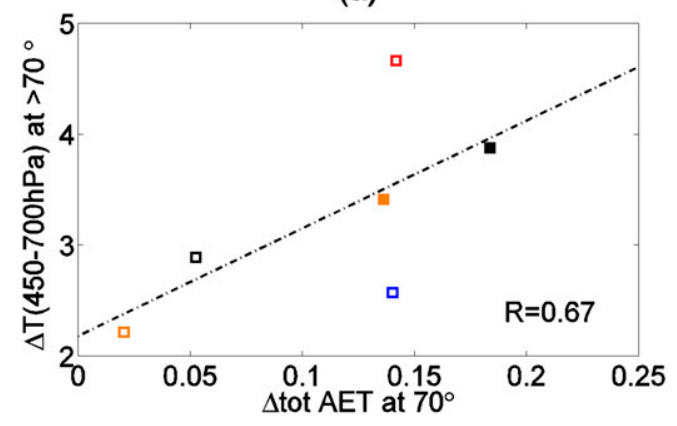

(c)

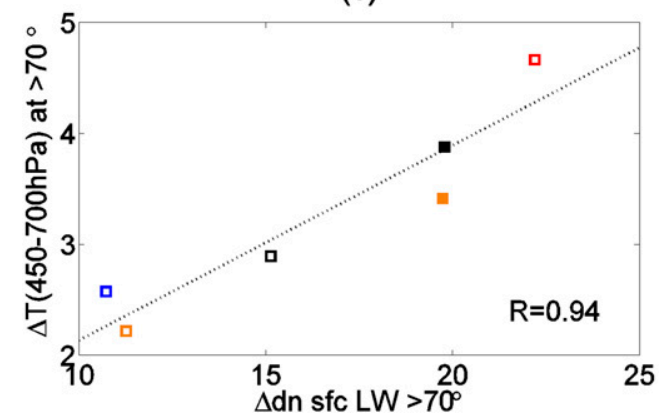

(b)

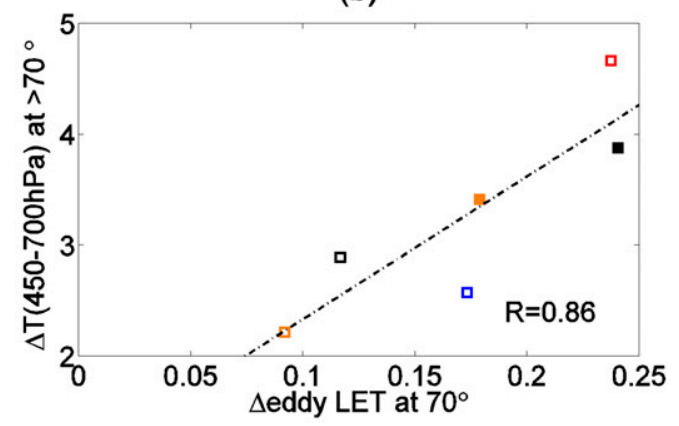

(d)

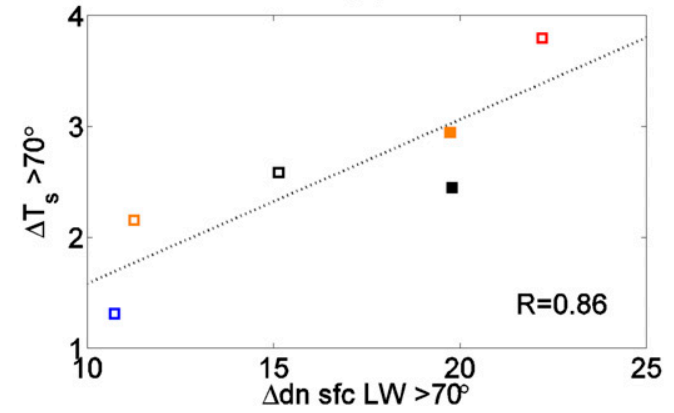

FIG. 2. Changes in midtropospheric temperature $(450-700 \mathrm{hPa})$ poleward of $70^{\circ}(\mathrm{K})$ vs changes in (a) atmospheric energy transport at $70^{\circ}$ and (b) eddy latent energy transport at $70^{\circ}(\mathrm{PW})$. Changes in downward longwave radiation at the surface poleward of $70^{\circ}\left(\mathrm{W} \mathrm{m}^{-2}\right)$ vs changes in (c) midtropospheric temperature $(450-700 \mathrm{hPa})$ and $(\mathrm{d})$ surface temperature poleward of $70^{\circ}(\mathrm{K})$. Simulations are color coded as in the legend of Fig. 3a. The open squares indicate the models with prescribed CRE.

indirectly from the energy budget for an atmospheric column: $\int_{-\pi / 2}^{\varphi}\left(2 \pi a^{2} \cos \varphi R\right) d \varphi$ where $\varphi$ is latitude, $a$ Earth's radius, and $R$ is the net TOA radiation. The midtropospheric warming can contribute to warming the polar surface through increasing the downward longwave radiation at the surface (Figs. 2c,d). An overall increase in the total AET at high latitudes is accomplished by an increase in latent heat transport by transient eddies (Fig. 2b). Partly compensating the enhanced total AET is the decrease in dry static energy transport resulting from a flattened temperature gradient.

For reference, most CMIP3 models project an increase in total AET equatorward of $70^{\circ} \mathrm{N}$, but the models do not agree on the sign poleward of $70^{\circ} \mathrm{N}$, despite a robust increase in the latent energy transport by transient eddies with global warming (Hwang et al. 2011). The increase in latent energy transport is expected because of an enhanced meridional humidity gradient, following the Clausius-Clapeyron relation (C-C relation), since water vapor increases preferentially in low latitudes due to an exponential increase of saturated humidity with temperature (Alexeev et al. 2005; Frierson et al. 2007; Graversen and Burtu 2016). Uncertainty in the sign of total AET at high latitudes originates from a large multimodel spread in the degree of polar amplification. Models with stronger polar amplification exhibit a larger reduction in dry static energy transport, which in some cases may overcompensate the increased latent energy transport, resulting in a reduced high-latitude total AET. Among CMIP3 models, the GFDL model, on which our model is based, is the one that projects the largest increase in the total AET throughout the globe. Feldl et al. (2017b) clearly demonstrate that the strength of surface albedo feedback modulates the ratio of latent to dry static energy transport in the extratropics. In the case with the strongest surface albedo feedback, the total AET is reduced due to an overcompensation by the decrease in dry static energy transport resulting from strong polar amplification. In the case with the moderate to weak surface albedo feedback, the total AET increases due to the dominance of the increase in latent energy transport over the decrease in dry static energy transport. Our model that features no surface albedo feedback gives rise to an increase in the total AET in the extratropics, consistent with the low surface albedo feedback case in Feldl et al. (2017b).

The midtropospheric polar warming, in particular, is suggested to originate from the midlatitude near-surface 
warming that propagates along climatological moist isentropes (Laliberté and Kushner 2014). Our results show a strong linear relationship between the $850-\mathrm{hPa}$ warming response averaged over $45^{\circ}-65^{\circ}$ and the midtropospheric warming averaged poleward of $70^{\circ}(R=0.85)$. Another origin for the midtropospheric polar warming could be warm equatorial air that is advected across the storm tracks by synoptic eddies and that subsides over the poles (Pauluis et al. 2008). The midtropospheric polar warming in our experiments is also strongly correlated with the warming response in the upper troposphere $(100-300 \mathrm{hPa})$ equatorward of $20^{\circ}(R=0.92)$. A subsequent study is needed to distinguish the contribution from the equatorial upper troposphere and midlatitude near-surface to polar midtropospheric warming.

In summary, in an aquaplanet setup with no surface albedo feedback, the equinox condition gives rise to a highly stable boundary layer in the polar region to form a bottom-heavy structured warming, resulting in strong polar amplification through the positive lapse rate feedback. In contrast, under annual-mean or seasonally varying insolation, the static stability in the polar region is so small that the lapse rate feedback is negative. However, the midtropospheric polar warming, which possibly originates from the midlatitude nearsurface warming and/or the tropical upper-tropospheric warming, may contribute to forming a weak polar amplification indirectly through the downward longwave radiation. In the next section, we demonstrate that the contrasting cloud response under the annual-mean and seasonally varying insolation is responsible for the varying degree of polar amplification in the two cases. In section $3 \mathrm{~d}$, the role of atmospheric energy transport on polar amplification will be discussed more extensively by using the radiative kernel technique.

\section{b. Cloud response}

In spite of the identical time-mean insolation, the degree of polar amplification is different between the models with annual-mean (ANN) and seasonally varying (SEA) insolation. To quantify the degree of polar amplification, we calculate polar amplification index (PAI), defined as the increase in surface temperature poleward of $70^{\circ}$ normalized by the change in global mean surface temperature. The PAI is 1.19 in ANN and 1.02 in SEA.

We find differences in the changes in top-ofatmosphere (TOA) cloud radiative effects $\left(\mathrm{CRE}_{\mathrm{TOA}}\right)$ between ANN and SEA (Fig. 3a; orange and black solid lines). In low latitudes, both models exhibit positive $\mathrm{CRE}_{\mathrm{TOA}}$ changes, due to a reduction of overall cloud amount (Fig. 3b). In contrast, high latitudes in both models exhibit negative $\mathrm{CRE}_{\mathrm{TOA}}$ changes due to an increase in low-level cloud amount, associated with increased relative humidity. However, the mid- to upperlevel cloud amount decreases since the relative humidity decreases there in association with the midtropospheric peak warming. The cloud amount changes in Fig. $3 \mathrm{~b}$ are consistent with previous studies (Vavrus 2004; Langen et al. 2012; Feldl et al. 2017a). Increased liquid water path over the middle to high latitudes associated with warming can also contribute to enhancing the negative $\mathrm{CRE}_{\mathrm{TOA}}$ in the extratropics (Ceppi et al. 2016). SEA exhibits a larger $\mathrm{CRE}_{\mathrm{TOA}}$ cooling response poleward of $65^{\circ}$ relative to ANN, which is consistent with the weaker polar amplification in SEA.

To confirm that the differences in $\mathrm{CRE}_{\mathrm{TOA}}$ changes are responsible for the varying PAI in ANN and SEA, we examine a corresponding prescribed cloud model that is described in section $2 \mathrm{a}$. When clouds are prescribed in SEA (denoted as SEAFC), the whole globe is warmed less except near the poles (Fig. 4a; black solid and dash-dotted lines). The contrast is largest in the tropics, leading to strong polar amplification in SEAFC $(\mathrm{PAI}=1.42)$. Stronger polar amplification in SEAFC relative to SEA can be also identified by comparing Fig. 1d with Fig. 4b. The CAM3 aquaplanet simulation with a seasonal cycle in Langen et al. (2012) that has weak cloud feedbacks exhibits a similar degree of polar amplification to our SEAFC. The prescribed cloud model of ANN (denoted as ANNFC) exhibits the same degree of polar amplification as SEAFC with PAI $=1.42$. The latitudinal profile of surface temperature response between ANNFC and SEAFC is indeed very similar (Fig. 4a; orange dash-dotted and black dash-dotted lines). Thus, the prescribed cloud models help to confirm that the contrast in the degree of polar amplification in ANN and SEA is the result of differences in the $\mathrm{CRE}_{\mathrm{TOA}}$ response. The reason for the differences in the $\mathrm{CRE}_{\mathrm{TOA}}$ response in ANN and SEA is discussed in section $3 \mathrm{c}$.

To better understand the role of cloud response on polar amplification, we additionally examine a partially prescribed cloud version of SEA. When clouds are allowed to respond in the tropics while being prescribed in the polar region (SEAFC_POL), the tropical surface warming is enhanced relative to SEAFC (Fig. 4a; red dash-dotted and black dash-dotted lines) as the $\mathrm{CRE}_{\mathrm{TOA}}$ changes cause warming in the low latitudes (Fig. 3a). The enhanced tropical warming leads to strong polar amplification, despite an absence of surface trapped warming (Fig. 4c). Rather, there is a midtropospheric peak in the polar warming as in SEA and ANN that is associated with weak polar amplification. Thus, one can deduce that it is the negative $\mathrm{CRE}_{\mathrm{TOA}}$ change in 
(a) $\triangle \mathrm{CRE}_{\mathrm{TOA}}$

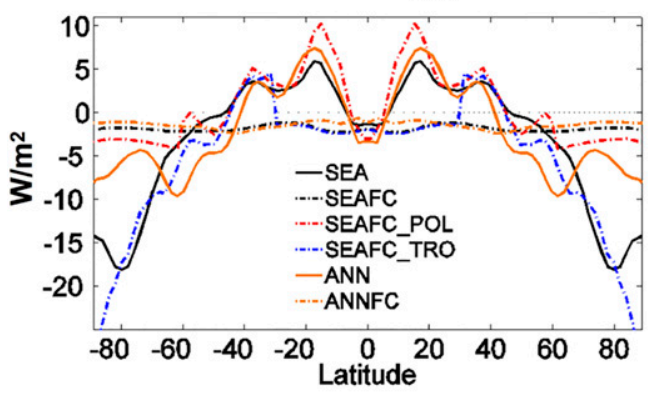

(c) $\triangle \mathrm{CRE}_{\mathrm{TOA}}\left(<20^{\circ}\right)$ vs mid-level $\Delta \mathrm{T}\left(>70^{\circ}\right)$

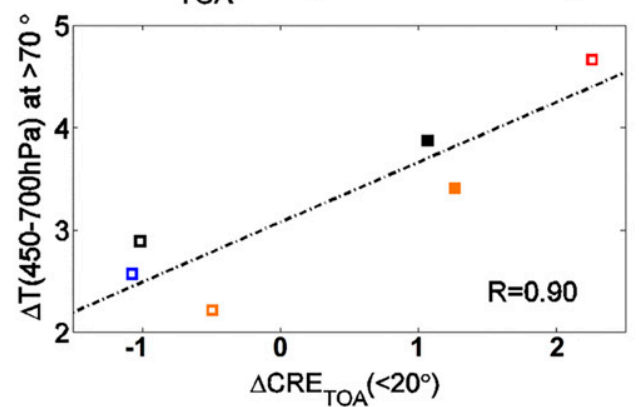

(b) $\Delta$ Cloud (\%)

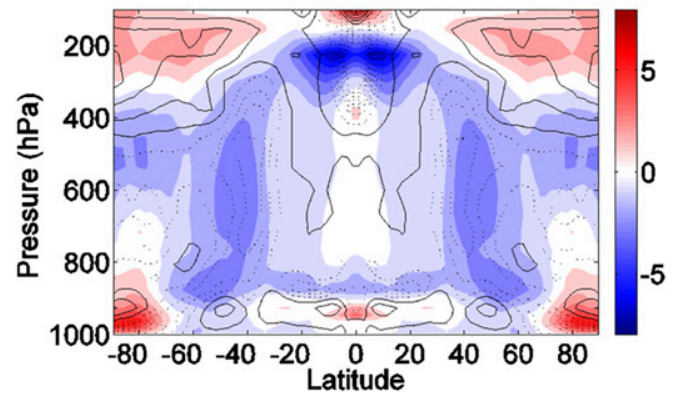

(d) $\Delta \mathrm{CRE}_{\mathrm{TOA}}\left(>60^{\circ}\right)$ vs PAI

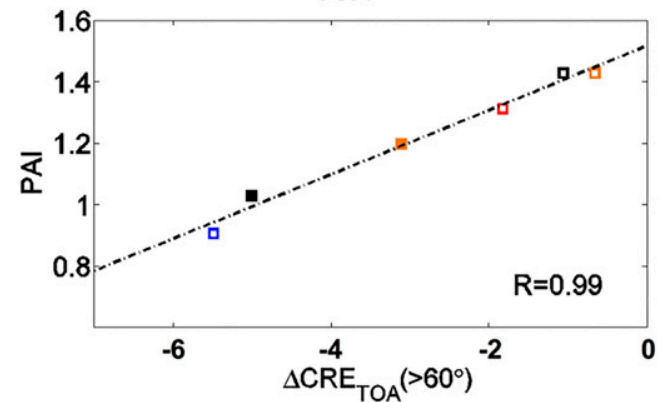

FIG. 3. Zonal- and time-mean responses to $2 \mathrm{xCO} 2$ in (a) cloud radiative effects at TOA $\left(\mathrm{CRE}_{\mathrm{TOA}} ; \mathrm{W} \mathrm{m}^{-2}\right)$ and (b) cloud fraction (\%) in SEA (shading) and ANN (contour; interval is 1\%). (c) Changes in midtropospheric temperature $(450-700 \mathrm{hPa})$ poleward of $70^{\circ}(\mathrm{K})$ vs area-mean CRE $\mathrm{TOA}_{\mathrm{A}}$ changes in the tropics $\left(<20^{\circ} ; \mathrm{W} \mathrm{m}^{-2}\right)$. (d) Polar amplification index (unitless) vs area-mean $\mathrm{CRE}_{\mathrm{TOA}}$ changes poleward of $60^{\circ}\left(\mathrm{W} \mathrm{m}^{-2}\right)$. Simulations are color coded as in the legend of (a). The open squares indicate the models with prescribed CRE.

the polar region that counteracts polar amplification in SEA and ANN. Conversely, when the clouds are allowed to respond in the polar region while being prescribed in the tropics (SEAFC_TRO), the degree of tropical surface warming is similar to SEAFC but the polar surface warming is significantly damped (Fig. 4a; blue dash-dotted and black dash-dotted lines) due to the negative $\mathrm{CRE}_{\mathrm{TOA}}$ change in the polar region (Fig. 3a). SEAFC_TRO presents only a weak upper tropospheric warming in the tropics (Fig. 4d), which then leads to a weak midtropospheric warming at the pole that is unable to cause any polar amplification at the surface. Indeed, the PAI in SEAFC_TRO is smaller than $1(\mathrm{PAI}=0.90)$. Although the CRE response in the polar region is negative in both SEA and SEAFC_TRO, SEA exhibits a larger polar amplification than SEAFC_TRO because of positive $\mathrm{CRE}_{\mathrm{TOA}}$ change in the tropics.

The partially prescribed cloud models provide insight into the mechanism of polar amplification in the absence of surface albedo feedback. In response to $2 \mathrm{xCO} 2$, the tropical surface warming is amplified by the positive $\mathrm{CRE}_{\mathrm{TOA}}$ changes. The warming response in the tropics is then maximized in the upper troposphere due to the moist adiabatic adjustment. In proportion to the magnitude of tropical warming, the poleward atmospheric energy transport increases to cause the midtropospheric polar warming. Hence, the $\mathrm{CRE}_{\mathrm{TOA}}$ increase in the tropics is highly correlated with the midtropospheric polar warming (Fig. 3c), which in turn contributes to polar surface warming through downward longwave radiation. The polar surface warming is, however, partially diminished by negative $\mathrm{CRE}_{\mathrm{TOA}}$ changes in high latitudes. In our model, the negative local $\mathrm{CRE}_{\mathrm{TOA}}$ changes overwhelm the effect of midtropospheric polar warming, thereby completely damping polar amplification in either SEA or ANN. Indeed, Fig. 3d shows that a larger negative polar $\mathrm{CRE}_{\mathrm{TOA}}$ change is accompanied by weaker polar amplification. The $\mathrm{CRE}_{\mathrm{TOA}}$ changes poleward of $60^{\circ}$ are almost perfectly correlated with the PAI. In contrast, the tropical $\mathrm{CRE}_{\mathrm{TOA}}$ change correlates poorly with the PAI $(R=-0.02)$ since the tropical $\mathrm{CRE}_{\mathrm{TOA}}$ change has only an indirect impact on polar amplification through the midtropospheric polar warming. Another potential reason for the poor correlation is that the tropical $\mathrm{CRE}_{\mathrm{TOA}}$ change accompanies warming not only in the polar region but also in the tropics, and hence it is difficult to create a large change in the meridional gradient. 
(a) $\Delta \mathrm{T}_{\mathrm{s}}$

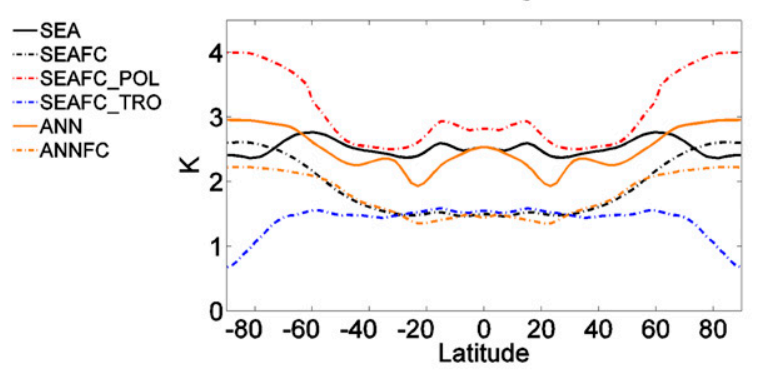

(c) SEAFC_POL
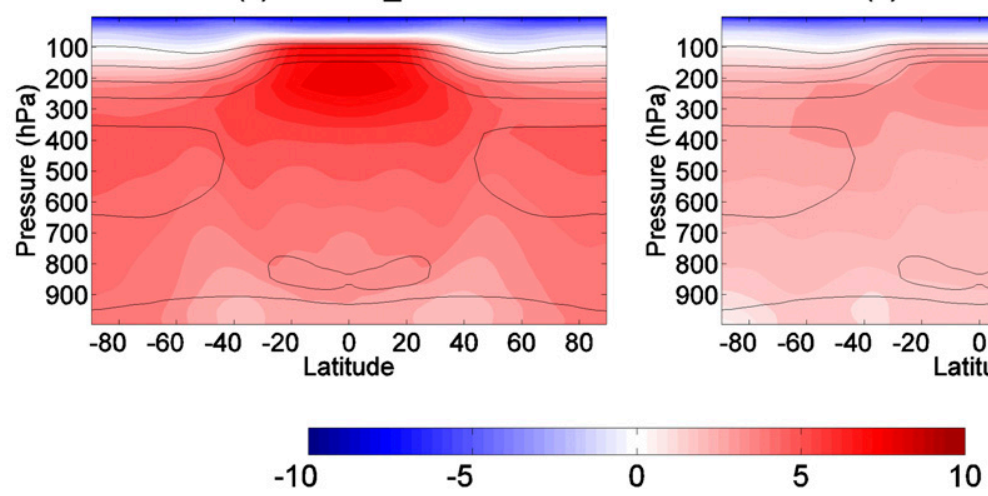

FIG. 4. (a) As in Fig. 1a, but for different simulations as noted in the legend. (b)-(d) As in Figs. 1b-d, but for

SEAFC, SEAFC_POL, and SEAFC_TRO, respectively. (b) SEAFC

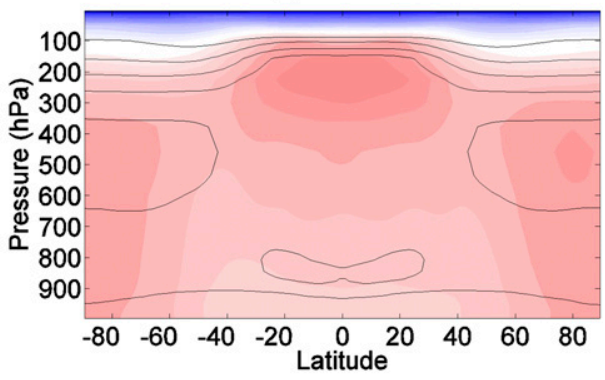

(d) SEAFC_TRO

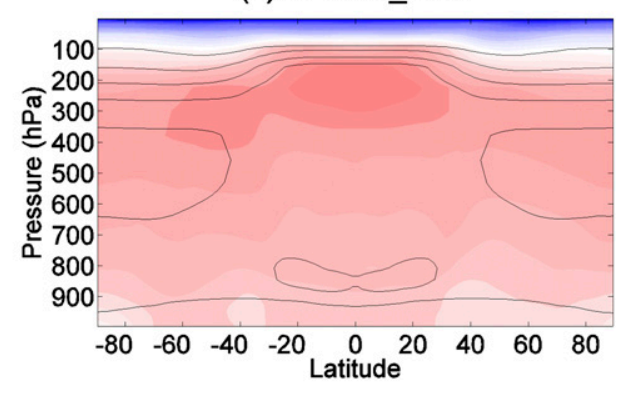
0
Therefore, the polar $\mathrm{CRE}_{\mathrm{TOA}}$ change is a more controlling factor for the degree of polar amplification than the tropical $\mathrm{CRE}_{\mathrm{TOA}}$ change.

\section{c. Seasonality of polar amplification}

To identify what causes the differences in the CRE response between ANN and SEA, we turn to the monthly response of SEA. In the polar region, the lowlevel cloud (defined as 680-1000 hPa) amount increases in the warm season [i.e., August-October for the Northern Hemisphere ( $\mathrm{NH})$ ], whereas it decreases in the cold season (i.e., February-April for the NH) (Fig. 5a). The low-level cloud amount reduction in the cold season is somewhat overestimated, but the overall feature is consistent with the CMIP3 ensemble projections (Vavrus et al. 2009). Our model calculates the cloud amount based on relative humidity following the prognostic scheme of Tiedtke (1993). Hence, the vertical profile of cloud fraction changes closely follows that of relative humidity (Figs. 6a,b). The relative humidity in the polar region increases below $600 \mathrm{hPa}$ in the warm season whereas it decreases throughout the troposphere, except near the surface, in the cold season (Fig. 6b). This contrast results from the distinctive seasonality in the vertical warming pattern (Fig. 6c), which possibly is caused by the seasonal differences in the mean circulation pattern. A strong descending motion in the cold season lowers the altitude of midtropospheric peak in polar warming and spreads the warming response to lower level (Fig. 6c). The consequent lowertropospheric warming in the polar region decreases the relative humidity, leading to a reduction of low-level cloud amount. Conversely, a weak ascending motion in the warm season elevates the altitude of the midtropospheric peak in polar warming, spreading the warming response to higher level (Fig. 6c). Despite a smaller warming response in the warm season below $450 \mathrm{hPa}$, the amount of specific humidity increase is larger in the warm season than the cold season due to the C-C relation (Fig. 6d), which contributes to an increase of relative humidity there. As a result, the polar region exhibits an increase in the low-level warm season cloud amount. Partly because of the nonlinear relationship between vapor pressure and temperature, the increase of low-level cloud amount in the warm season is greater than the decrease in the cold season, so that the annualmean low-level cloud amount increases in the polar region in SEA (Fig. 5a). In contrast, the time-mean response of ANN exhibits a reduction of the low-level cloud amount in the polar region (Fig. 5a).

As a result of the increase in low-level cloud amount in the polar warm season, there is a large negative 
(a) $\Delta$ Low cloud fraction $(\%)$
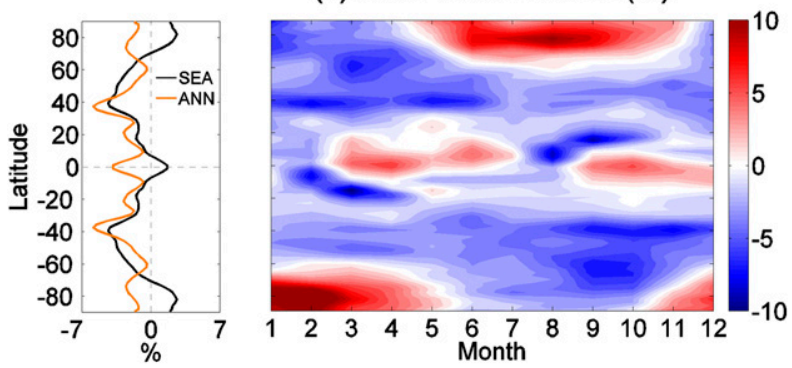

(b) $\Delta \mathrm{CRE}_{\mathrm{sfc}}\left(\mathrm{W} / \mathrm{m}^{2}\right)$
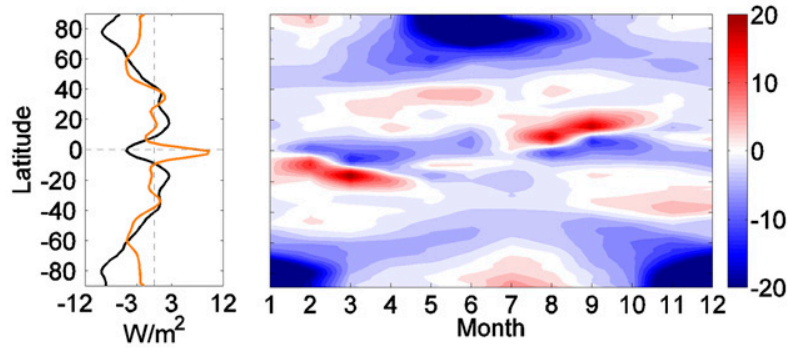

(c) $\Delta \mathrm{T}_{\mathrm{s}}(\mathrm{K})$
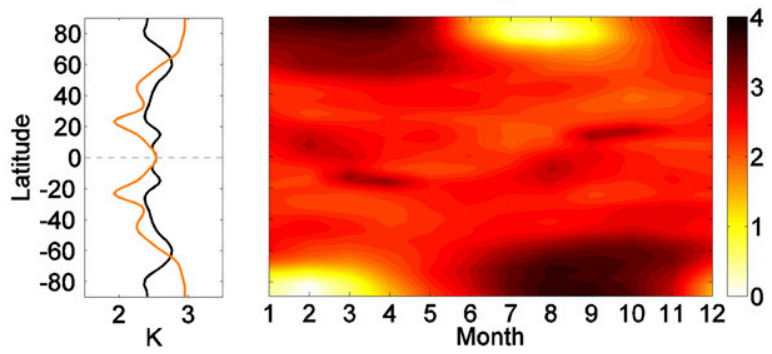

FIG. 5. (Top) low cloud fraction (\%), (middle) cloud radiative effects at the surface $\left(\mathrm{W} \mathrm{m}^{-2}\right)$, and (bottom) surface temperature (K). In the left column, black and orange lines are the annual averages of zonal-mean responses for SEA and ANN, respectively. The right column indicates the monthly zonally averaged responses in SEA.

change in CRE at the surface (denoted as $\mathrm{CRE}_{\mathrm{sfc}}$ ) that counteracts the polar surface warming response (Fig. 5b). The negative $\mathrm{CRE}_{\text {sfc }}$ response in the northern high latitudes peaks from May to July when the greatest insolation reaches the North Pole. Changes in cloud amount in the dark months have only a limited impact on radiative fluxes; accordingly, the increase of northern high-latitude low-level cloud amount from September to November is accompanied by negligible $\mathrm{CRE}_{\mathrm{sfc}}$ response (Figs. 5a,b). The large seasonality in the polar $\mathrm{CRE}_{\text {sfc }}$ response results in polar surface warming with a distinct seasonality (Figs. 5c and 7). The polar surface warming response lags the $\mathrm{CRE}_{\text {sfc }}$ response by two to three months due to the time it takes to heat up the ocean mixed layer. The monthly variation of polar surface warming in Fig. 5c indicates that the warming is most amplified in the cold season (i.e., March in the North Pole and August in the South Pole) and most damped in the warm season (i.e., August in the North Pole and February in the South Pole). That is, the largest negative tendency of surface temperature response exists in June in the North Pole and November in the South Pole, corresponding to the timing of the largest negative $\mathrm{CRE}_{\text {sfc }}$ response. This is because the $\mathrm{CRE}_{\text {sfc }}$ response corresponds to the time tendency of surface temperature response.

Comparison of monthly PAI between SEA and SEAFC in Fig. 7 clearly shows that polar amplification is weakest in the warm season in SEA due to the large negative change in $\mathrm{CRE}_{\mathrm{sfc}}$. The PAI is larger in SEAFC than in SEA throughout the year, despite negligible $\mathrm{CRE}_{\mathrm{sfc}}$ response in the polar region in the cold season (Fig. 5b). This is because the whole globe is generally warmed less in SEAFC (Fig. 4a), leading to a larger PAI for the same degree of polar warming. The results indicate that the strong seasonality of local $\mathrm{CRE}_{\mathrm{sfc}}$ response, which originates from the intrinsic large seasonality of insolation in the polar region, is responsible for the seasonality of polar amplification in SEA. In more comprehensive models with sea ice, the temperature inversions occur in the boundary layer in the cold season, effectively contributing to strong winter polar amplification through the lapse rate feedback (Bintanja et al. 2011; Pavelsky et al. 2011; Pithan and Mauritsen 2014). In our simulations with no sea ice, it is the weak $\mathrm{CRE}_{\mathrm{sfc}}$ response that leads to the enhanced polar amplification in winter.

In $\mathrm{ANN}$, there is a small negative $\mathrm{CRE}_{\mathrm{sfc}}$ response in the polar region, despite a reduction of low-level cloud amount (Figs. 5a,b), which is presumably due to the increase of liquid water path (Ceppi et al. 2016). On the other hand, the annual-mean SEA exhibits a large negative $\mathrm{CRE}_{\mathrm{sfc}}$ response in the polar region due to its nonlinear response with season (Fig. 5b). As a result, the PAI in ANN is larger than the annual-mean PAI in SEA (Fig. 7). Note that the strength of lapse rate feedback between SEA and ANN is similar (Fig. S1) because of the similar time-mean static stability in the respective control climate (Figs. 1c,d).

\section{d. Feedbacks and remote effects}

The radiative kernel technique enables a linear decomposition of climate response into the relative contributions from individual feedbacks. In particular, we utilize the radiative kernel technique to examine the role of the meridional structure of feedbacks, heat transport, radiative forcing, and possibly nonlinearities in controlling the meridional profile of surface temperature response. Following Feldl and Roe (2013a), 
(a) $\Delta$ Cloud fraction

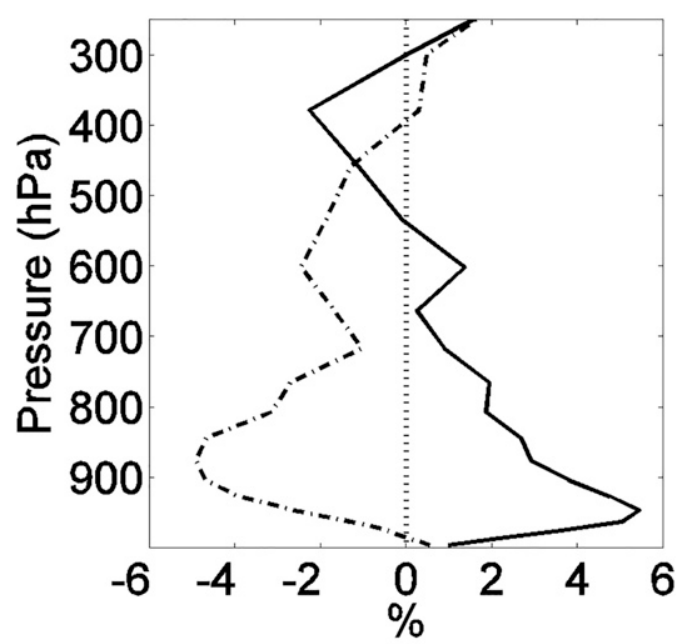

(c) $\Delta$ Temp

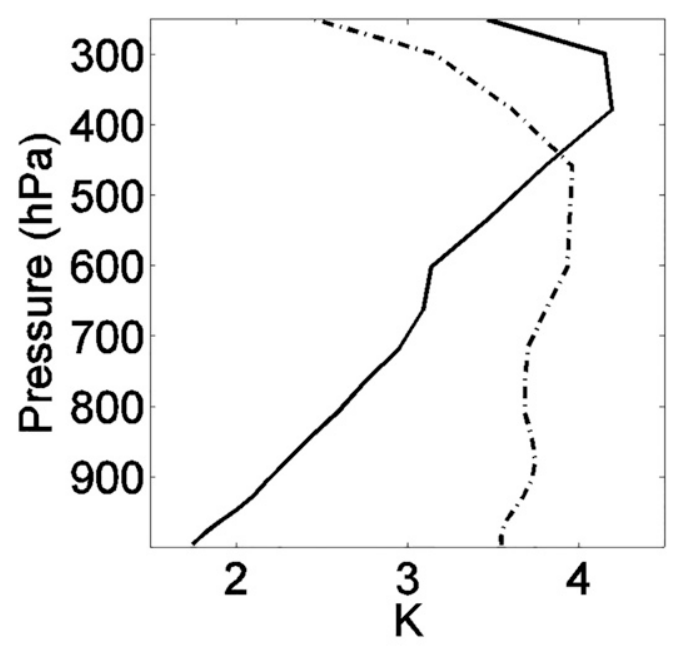

(b) $\Delta \mathrm{RH}$

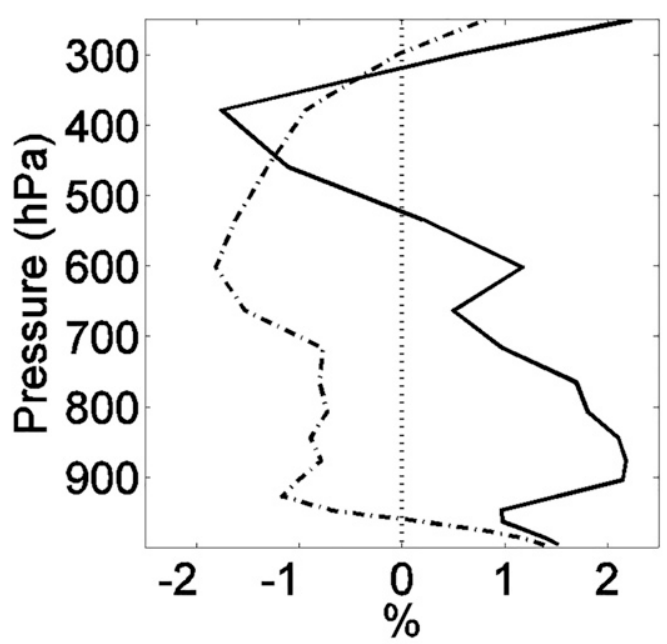

(d) $\Delta \mathrm{SH}$

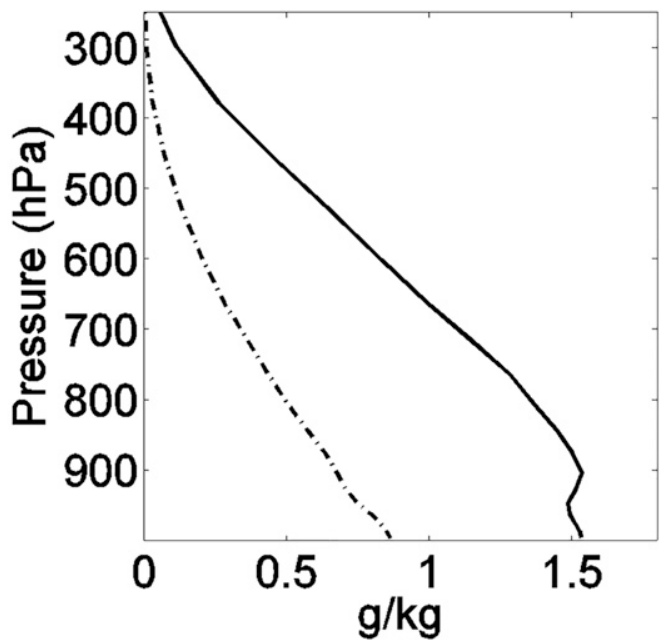

FIG. 6. Changes in (a) cloud fraction (\%), (b) relative humidity (\%), (c) temperature (K), and (d) specific humidity $\left(\mathrm{g} \mathrm{kg}^{-1}\right)$ averaged over poleward of $60^{\circ} \mathrm{N}$ for August-October (solid) and February-April (dashed) in SEA.

Eq. (1) is reorganized to solve for the zonal-mean surface temperature response, by normalizing the terms in the energy balance by the global-mean Planck feedback $\left(\overline{\lambda_{p}}\right)$ :

$$
\Delta T_{s}=\frac{1}{\overline{\lambda_{p}}}\left[\Delta R-\left(\lambda_{p}^{\prime} \Delta T_{s}+\sum_{i} \lambda_{\mathrm{NP}_{i}} \Delta T_{s}\right)-\Delta R_{f}\right]
$$

In Eq. (2), $\lambda_{p}{ }^{\prime}$ is the local deviation from the globalmean Planck feedback, and $\lambda_{\mathrm{NP}}$ is the non-Planck feedbacks including lapse rate, water vapor, and cloud feedbacks. Note that there is no surface albedo feedback in our experiments. These individual contributions are presented in Fig. 8; they are mostly consistent with previous studies in Feldl et al. $(2017 \mathrm{a}, \mathrm{b})$. The sum of all terms (gray line) reproduces the actual response (black line), suggesting only a small nonlinearity in both SEA and SEAFC, thereby allowing us to examine the relative importance of individual contributions to the meridional pattern of surface warming. The Planck feedback is calculated from the surface temperature response applied uniformly with height in the troposphere. Following the Stefan-Boltzmann law, the outgoing longwave radiation increases with temperature, so that the Planck feedback cools the warm tropics and warms the high latitudes (violet in Fig. 8). The Planck feedback profile is nearly the same between SEA and SEAFC because their control climate states are similar. 


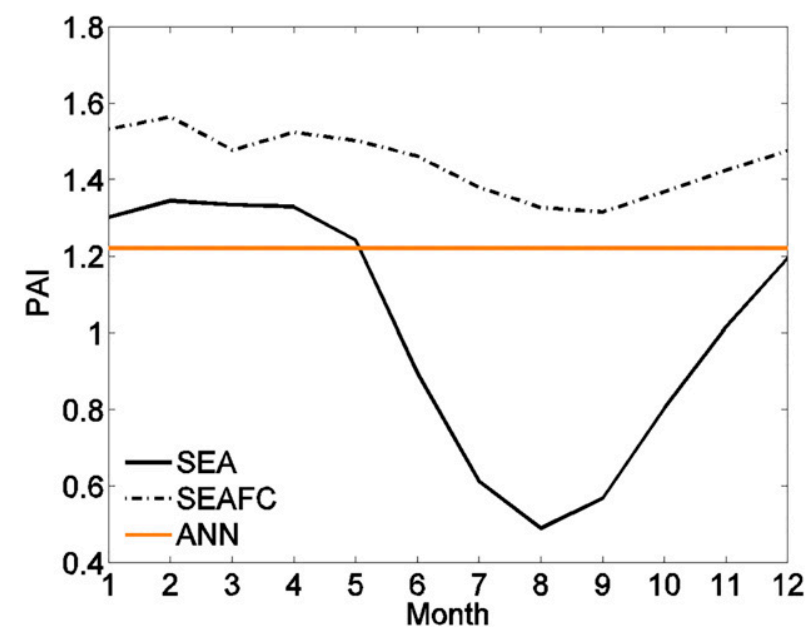

FIG. 7. Monthly polar amplification index (unitless) in SEA (black solid), SEAFC (black dashed), and ANN (orange solid) for the NH.

As discussed in section 3b, the cloud feedback (blue line) is positive in the tropics and negative in the polar region in SEA, while it nearly vanishes in SEAFC. Note that the masking effects are eliminated from $\mathrm{CRE}_{\mathrm{TOA}}$ changes when calculating the kernel's cloud feedback, so the two terms are slightly different (contrast Figs. 3a and 8). One may attempt to predict the surface temperature response pattern in SEAFC by removing the cloud feedback contribution from the total response in SEA. However, this prediction is imperfect (Fig. S2) because the large differences in cloud feedback in SEA and SEAFC influence other feedbacks.

The cloud feedback primarily strengthens the equator-to-pole energy imbalance in SEA, so that the resultant energy transport term is greater in SEA relative to SEAFC. The energy transport term exhibits a pattern of low-latitude cooling and high-latitude warming (pink in Fig. 8), consistent with an increase of energy transport (Fig. 2a). The larger increase in energy transport in SEA contributes to a larger polar warming compared to SEAFC. This explains why the SEAFC prediction by removing the cloud feedback contribution from the SEA response overestimates the actual degree of polar amplification in SEAFC (Fig. S2).

The lapse rate feedback is associated with the vertical structure of atmospheric warming (Bintanja et al. 2012). It generally serves as a negative feedback in the tropics, which exhibit a top-heavy warming profile, while it serves as a positive feedback in the polar region, which exhibits a bottom-heavy warming profile (Serreze et al. 2009; Screen et al. 2012; Pithan and Mauritsen 2014). However, in our experiments, the lapse rate feedback is globally negative (orange in Fig. 8), consistent with the low-albedo simulation in Feldl et al. (2017a). The lapse rate feedback in the polar region is positive only in EQN (Fig. S1). This is because the lower-tropospheric static stability in all experiments other than EQN is not large enough to form an inversion in the polar region, due to the absence of surface albedo feedback. Instead of a bottom-heavy warming, the polar region in SEA presents the peak warming in the midtroposphere in association with an increase of energy transport from the low latitudes (Fig. 1d). The negative lapse rate feedback in the polar region is larger in SEA than in SEAFC. This is because of a pronounced midtropospheric peak warming in SEA that is induced by a correspondingly larger increase in the energy transport (pink in Fig. 8) resulting from the cloud feedback that enhances the energy imbalance between the tropics and the extratropics. The negative lapse rate feedback cannot induce any warming in the polar region. However, its negative effect is larger in the tropics than in the polar region in both SEA and SEAFC, thereby contributing to the meridional pattern of polar amplification.

The positive cloud feedback in the tropics results in the warmer tropics, thereby strengthening the positive water vapor feedback (green) in SEA relative to SEAFC. The $2 \mathrm{xCO}_{2}$ forcing (red) in both SEA and SEAFC produces more warming in the low latitudes than in the high latitudes. The forcing term in SEAFC is more meridionally flat, consistent with the work of Huang et al. (2016), where cloud effects are shown to contribute to creating forcing inhomogeneity. The forcing contribution in SEA is comparable to that shown in Feldl et al. (2017a; see their Fig. 8). These cloud feedback, water vapor feedback, and forcing effects act to enhance the meridional temperature gradient, while the remaining terms such as the Planck feedback, lapse rate feedback, and energy transport terms act to induce polar amplification. Even though the energy transport term and lapse rate feedback lead to greater polar amplification in SEA than in SEAFC, the negative cloud feedback in the polar region effectively damps the polar surface warming in SEA. Conversely, there is little change in the energy transport in SEAFC due to the absence of cloud feedback, but the lapse rate feedback leads to polar amplification. As a result, there is only a weak signature of polar amplification in SEA whereas SEAFC exhibits a clear indication of polar amplification. The feedback analysis corroborates the discussion in section $3 b$.

In models with a surface albedo feedback, the temperature feedback (both Planck and lapse rate feedback) is the most important contributor to the amplified warming response in the polar region (Pithan and Mauritsen 2014). In the absence of a surface albedo feedback, our aquaplanet simulation with a seasonal 
(a) SEA

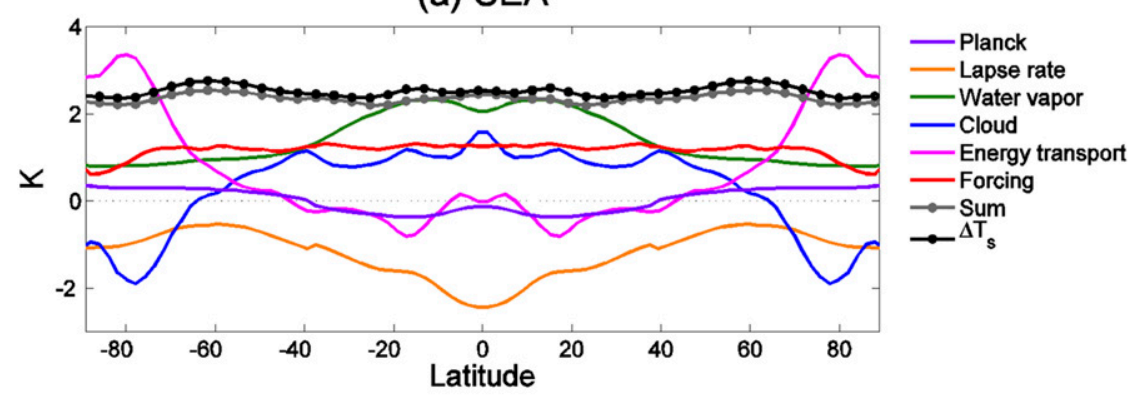

(b) SEAFC

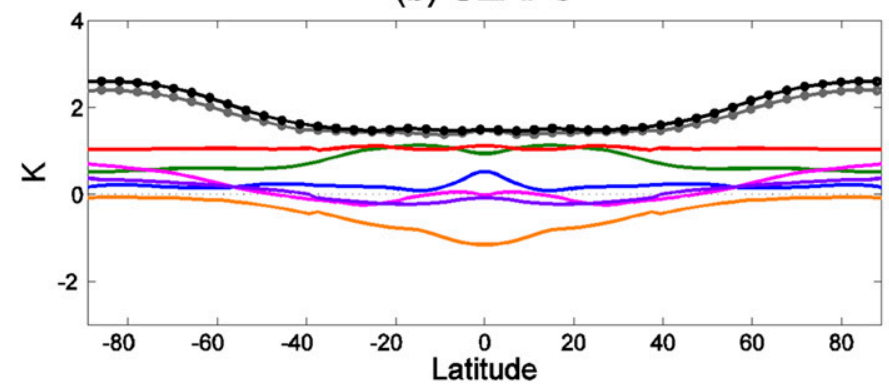

FIG. 8. Zonal- and time-mean partial temperature changes $(\mathrm{K})$ attributed to $2 \mathrm{xCO}_{2}$ forcing (red), Planck (violet), transport (pink), water vapor feedback (green), cloud feedback (blue), and lapse rate feedback (orange), weighted by the global-mean Planck feedback following Feldl and Roe (2013a), for (a) SEA and (b) SEAFC. The sum of colored lines is shown in gray circled lines and the total surface temperature change, shown as black solid and dash-dotted lines in Fig. 4a, in black circled lines.

cycle highlights an important role played by the energy transport (Fig. 8; pink line). An increase of energy transport induces a midtropospheric peak warming in the polar region, which in turn leads to the lapse rate feedback being negative. Thus, the energy transport term can contribute to polar amplification through the midtropospheric peak warming, but can counteract polar amplification by making the lapse rate feedback negative. The energy transport term generates polar warming at the expense of tropical cooling in order to reduce the large equator-to-pole energy imbalance (i.e., heating in the tropics and cooling in the polar region), which is induced by the cloud feedback in SEA. Hence, in the case where large polar warming results from the energy transport, it is most likely that there exists a large negative feedback to cancel out the polar warming. Conversely, if there is small negative cloud feedback in the polar region, there is no need for an increase of energy transport. Hence, the sum of cloud feedback and energy transport term is expected to be almost meridionally flat. In the case of a smaller increase of energy transport, the midtropospheric peak warming will be less pronounced, and the lapse rate feedback in the polar region will be less negative. Since the lapse rate feedback is far more negative in the tropics, this may lead to greater polar amplification, as is the case of SEAFC. Pieced together, the energy transport increase itself can lead to polar warming through the midtropospheric warming but whether its effect ultimately contributes to polar amplification or not is highly uncertain due to its indirect impact on the lapse rate feedback.

\section{Summary and discussion}

In this paper, we adopt aquaplanet simulations coupled to a slab ocean under different insolation conditions to disentangle the mechanism for polar amplification in the absence of surface albedo feedback. The insolation condition is manipulated from the equinox (denoted as EQN) to the annual mean (denoted as ANN) to the seasonally varying (denoted as SEA). We examine the pattern of surface warming in response to a doubling of $\mathrm{CO}_{2}(2 \mathrm{xCO} 2)$.

The EQN experiment exhibits the most polar amplified warming, primarily due to the large static stability in the boundary layer (because no insolation reaches the pole throughout a year) that traps the warming response near the surface. Even though the static stability is not as large as in the real boreal winter Arctic with an inversion layer, the resultant bottom-heavy warming is 
responsible for a positive lapse rate feedback, which amplifies the polar surface warming. In contrast, the ANN and SEA experiments do not exhibit any maxima in static stability in the boundary layer, and the polar warming response is maximized in the midtroposphere, resulting in a negative lapse rate feedback in the polar region. This sensitivity of climate feedbacks on control climate has also been identified in comprehensive models ( $\mathrm{Hu}$ et al. 2017). The midtropospheric polar warming can induce a weak polar surface warming through an increase of downward longwave radiative flux, but the polar surface warming in ANN is much weaker than in EQN. In SEA, the effect of midtropospheric warming on the surface is cancelled by a large negative $\mathrm{CRE}_{\mathrm{TOA}}$ in the polar region, and hence there is no indication of polar amplification. Our result that EQN exhibits by far the strongest polar amplified surface warming pattern (3.5 times more polar amplified than in ANN) suggests that the positive lapse rate feedback is the most efficient mechanism for polar amplification. However, even in the absence of a positive lapse rate feedback, the surface warming pattern can be polar amplified as in ANN.

Polar amplification in ANN is induced by the midtropospheric polar warming, which is largely caused by condensational heating due to an increase of eddy latent heat transport at high latitudes. In particular, the near-surface midlatitude warming and/or the uppertropospheric tropical warming are suggested to be the origin of midtropospheric polar warming (Pauluis et al 2008; Laliberté and Kushner 2014). The uppertropospheric warming in the tropics is amplified by the positive tropical $\mathrm{CRE}_{\mathrm{TOA}}$ response, so that inhibiting the tropical CRE weakens the midtropospheric polar warming. In contrast, the polar $\mathrm{CRE}_{\mathrm{TOA}}$ response is negative, so that inhibiting the polar CRE strengthens the polar surface warming. This influence of cloud adjustments on the degree of polar amplification suggests the need for better cloud parameterization in order to enhance the skill of climate models in simulating the polar amplification feature.

In sum, the surface warming pattern in response to $2 \mathrm{xCO} 2$ can be polar amplified in the absence of surface albedo feedback, consistent with previous studies (Alexeev et al. 2005; Langen et al. 2012). We note that other mechanisms besides the surface albedo feedback, such as ocean heat uptake and storage, can contribute to the differences between our idealized simulations and more comprehensive models and observation. Similar to our experiments, the CAM3 aquaplanet simulation with a seasonal cycle in Langen et al. (2012), which has a weaker cloud feedback than our AM2, shows a similar degree and pattern of polar amplification to SEAFC
(Fig. 4a). However, the annual-mean insolation experiment of Alexeev et al. (2005) shows much larger polar amplification due to a colder and more stable control climatology than our ANN. Polar surface warming is modulated by interactions among multiple climate feedbacks. For instance, the meridional profile of CRE response (which is positive in the tropics and negative in the polar regions) gives rise to a larger tropical warming that induces a larger increase in eddy latent heat transport, thereby more effectively warming the midtropospheric polar region. This would tend to enhance the polar surface warming. The larger the negative polar $\mathrm{CRE}$, the larger the increase in total atmospheric energy transport and the larger the polar surface warming. However, a large negative polar CRE also acts to directly counteract the polar surface warming. Thus, there is a competing effect between the atmospheric energy transport and local CRE. Furthermore, even though a larger midtropospheric warming is expected to contribute to surface warming, its effect on the lapse rate feedback is negative by inducing a top-heavy warming rather than a bottom-heavy warming (Singh et al. 2017). Another complication arises from the large compensation between latent energy transport and dry static energy transport. A larger polar surface warming would be induced by a larger increase in latent energy transport, which would be accompanied by a larger reduction in dry static energy transport that would in turn act to reduce the polar surface warming. However, the change in dry static energy transport cannot perfectly compensate for the increased latent energy transport (Merlis and Henry 2018). This implies that a more controlled experiment is needed to identify how one feedback interacts with other feedbacks and energy transport, and what determines the degree of their compensation.

Acknowledgments. The authors thank Jennifer Kay and Olivier Pauluis for helpful discussions. S.M.K., D.K., and Y.S. were supported by Basic Science Research Program through the National Research Foundation of Korea (NRF) funded by the Ministry of Science, ICT and Future Planning (2016R1A1A3A04005520). The model data in this study can be obtained at https://github. com/doyeonkim12/UNIST_CDL_POLAR_AMP. The authors declare no conflict of interest.

\section{REFERENCES}

Alexeev, V. A., P. L. Langen, and J. R. Bates, 2005: Polar amplification of surface warming on an aquaplanet in "ghost forcing" experiments without sea ice feedbacks. Climate Dyn., 24, 655-666, https://doi.org/10.1007/s00382-005-0018-3.

Anderson, J. L., and Coauthors, 2004: The new GFDL global atmosphere and land model AM2-LM2: Evaluation with 
prescribed SST simulations. J. Climate, 17, 4641-4673, https:// doi.org/10.1175/JCLI-3223.1.

Arrhenius, S., 1896: XXXI. On the influence of carbonic acid in the air upon the temperature of the ground. Philos. Mag., 41, 237276, https://doi.org/10.1080/14786449608620846.

Bekryaev, R. V., I. V. Polyakov, and V. A. Alexeev, 2010: Role of polar amplification in long-term surface air temperature variations and modern Arctic warming. J. Climate, 23, 3888-3906, https://doi.org/10.1175/2010JCLI3297.1.

Bintanja, R., R. G. Graversen, and W. Hazeleger, 2011: Arctic winter warming amplified by the thermal inversion and consequent low infrared cooling to space. Nat. Geosci., 4, 758-761, https://doi.org/10.1038/ngeo1285.

— E. C. Van der Linden, and W. Hazeleger, 2012: Boundary layer stability and Arctic climate change: A feedback study using EC-Earth. Climate Dyn., 39, 2659-2673, https://doi.org/ 10.1007/s00382-011-1272-1.

Cai, M., 2005: Dynamical amplification of polar warming. Geophys. Res. Lett., 32, L22710, https://doi.org/10.1029/2005GL024481.

Ceppi, P., D. L. Hartmann, and M. J. Webb, 2016: Mechanisms of the negative shortwave cloud feedback in middle to high latitudes. J. Climate, 29, 139-157, https://doi.org/10.1175/ JCLI-D-15-0327.1.

Chung, C. E., and P. Räisänen, 2011: Origin of the Arctic warming in climate models. Geophys. Res. Lett., 38, L21704, https:// doi.org/10.1029/2011GL049816.

Cohen, J. L., J. C. Furtado, M. A. Barlow, V. A. Alexeev, and J. E. Cherry, 2012: Arctic warming, increasing snow cover and widespread boreal winter cooling. Environ. Res. Lett., 7, 014007, https://doi.org/10.1088/1748-9326/7/1/014007.

Cronin, T. W., and M. F. Jansen, 2016: Analytic radiative-advective equilibrium as a model for high-latitude climate. Geophys. Res. Lett., 43, 449-457, https://doi.org/10.1002/2015GL067172.

Feldl, N., and G. H. Roe, 2013a: The nonlinear and nonlocal nature of climate feedbacks. J. Climate, 26, 8289-8304, https://doi.org/ 10.1175/JCLI-D-12-00631.1.

$\longrightarrow$, and -2013 b: Four perspectives on climate feedbacks. Geophys. Res. Lett., 40, 4007-4011, https://doi.org/10.1002/ grl.50711.

_, S. Bordoni, and T. M. Merlis, 2017a: Coupled high-latitude climate feedbacks and their impact on atmospheric heat transport. J. Climate, 30, 189-201, https://doi.org/10.1175/ JCLI-D-16-0324.1.

— B. T. Anderson, and S. Bordoni, 2017b: Atmospheric eddies mediate lapse rate feedback and Arctic amplification. J. Climate, 30, 9213-9224, https://doi.org/10.1175/JCLI-D-16-0706.1.

Frierson, D. M. W., I. M. Held, and P. Zurita-Gotor, 2007: A grayradiation aquaplanet moist GCM. Part II: Energy transports in altered climates. J. Atmos. Sci., 64, 1680-1693, https://doi.org/ 10.1175/JAS3913.1.

Graversen, R. G., and M. Wang, 2009: Polar amplification in a coupled climate model with locked albedo. Climate Dyn., 33, 629-643, https://doi.org/10.1007/s00382-009-0535-6.

_- and M. Burtu, 2016: Arctic amplification enhanced by latent energy transport of atmospheric planetary waves. Quart. J. Roy. Meteor. Soc., 142, 2046-2054, https://doi.org/10.1002/qj.2802.

—, P. L. Langen, and T. Mauritsen, 2014: Polar amplification in CCSM4: Contributions from the lapse rate and surface albedo feedbacks. J. Climate, 27, 4433-4450, https://doi.org/10.1175/ JCLI-D-13-00551.1.

Hansen, J., and Coauthors, 2005: Efficacy of climate forcings. J. Geophys. Res., 110, D18104, https://doi.org/10.1029/ 2005JD005776.
Hofer, S., A. J. Tedstone, X. Fettweis, and J. L. Bamber, 2017: Decreasing cloud cover drives the recent mass loss on the Greenland ice sheet. Sci. Adv., 3, e1700584, https://doi.org/ 10.1126/sciadv.1700584.

Holland, M. M., and C. M. Bitz, 2003: Polar amplification of climate change in coupled models. Climate Dyn., 21, 221-232, https:// doi.org/10.1007/s00382-003-0332-6.

Hu, X., P. C. Taylor, M. Cai, S. Yang, Y. Deng, and S. Sejas, 2017: Inter-model warming projection spread: Inherited traits from control climate diversity. Sci. Rep., 7, 4300, https://doi.org/ 10.1038/s41598-017-04623-7.

Huang, Y., X. Tan, and Y. Xia, 2016: Inhomogeneous radiative forcing of homogeneous greenhouse gases. J. Geophys. Res. Atmos., 121, 2780-2789, https://doi.org/10.1002/2015JD024569.

Hwang, Y.-T., D. M. W. Frierson, and J. E. Kay, 2011: Coupling between Arctic feedbacks and changes in poleward energy transport. Geophys. Res. Lett., 38, L17704, https://doi.org/ 10.1029/2011GL048546.

Inoue, J., and M. E. Hori, 2011: Arctic cyclogenesis at the marginal ice zone: A contributory mechanism for the temperature amplification? Geophys. Res. Lett., 38, L12502, https://doi.org/ 10.1029/2011GL047696.

IPCC, 2007: Climate Change 2007: The Physical Science Basis. Cambridge University Press, 996 pp.

Kay, J. E., M. M. Holland, C. M. Bitz, E. Blanchard-Wrigglesworth, A. Gettelman, A. Conley, and D. Bailey, 2012: The influence of local feedbacks and northward heat transport on the equilibrium Arctic climate response to increased greenhouse gas forcing. J. Climate, 25, 5433-5450, https://doi.org/10.1175/ JCLI-D-11-00622.1.

Laliberté, F., and P. J. Kushner, 2014: Midlatitude moisture contribution to recent Arctic tropospheric summertime variability. J. Climate, 27, 5693-5707, https://doi.org/10.1175/ JCLI-D-13-00721.1.

Langen, P. L., R. G. Graversen, and T. Mauritsen, 2012: Separation of contributions from radiative feedbacks to polar amplification on an aquaplanet. J. Climate, 25, 3010-3024, https:// doi.org/10.1175/JCLI-D-11-00246.1.

Lu, J., and M. Cai, 2009: Seasonality of polar surface warming amplification in climate simulations. Geophys. Res. Lett., $\mathbf{3 6}$, L16704, https://doi.org/10.1029/2009GL040133.

Manabe, S., and R. T. Wetherald, 1975: The effects of doubling the $\mathrm{CO}_{2}$ concentration on the climate of a general circulation model. J. Atmos. Sci., 32, 3-15, https://doi.org/10.1175/ 1520-0469(1975)032<0003:TEODTC >2.0.CO;2.

__, R. J. Stouffer, M. J. Spelman, and K. Bryan, 1991: Transient responses of a coupled ocean-atmosphere model to gradual changes of atmospheric $\mathrm{CO}_{2}$. Part I. Annual mean response. J. Climate, 4, 785-818, https://doi.org/10.1175/ 1520-0442(1991)004<0785:TROACO >2.0.CO;2.

— M. J. Spelman, and R. J. Stouffer, 1992: Transient responses of a coupled ocean-atmosphere model to gradual changes of atmospheric $\mathrm{CO}_{2}$. Part II: Seasonal response. J. Climate, $\mathbf{5}$, 105-126, https://doi.org/10.1175/1520-0442(1992)005<0105: TROACO $>2.0 . \mathrm{CO} ; 2$.

Merlis, T. M., and M. Henry, 2018: Simple estimates of polar amplification in moist diffusive energy balance models. J. Climate, https://doi.org/10.1175/JCLI-D-17-0578.1, in press.

Pauluis, O., A. Czaja, and R. Korty, 2008: The global atmospheric circulation on moist isentropes. Science, 321, 1075-1078, https://doi.org/10.1126/science.1159649.

Pavelsky, T. M., J. Boé, A. Hall, and E. J. Fetzer, 2011: Atmospheric inversion strength over polar oceans in winter regulated 
by sea ice. Climate Dyn., 36, 945-955, https://doi.org/10.1007/ s00382-010-0756-8.

Perovich, D. K., J. A. Richter-Menge, K. F. Jones, and B. Light, 2008: Sunlight, water, and ice: Extreme Arctic sea ice melt during the summer of 2007. Geophys. Res. Lett., 35, L11501, https://doi.org/10.1029/2008GL034007.

Pithan, F., and T. Mauritsen, 2014: Arctic amplification dominated by temperature feedbacks in contemporary climate models Nat. Geosci., 7, 181-184, https://doi.org/10.1038/ngeo2071.

Screen, J. A., and I. Simmonds, 2010: The central role of diminishing sea ice in recent Arctic temperature amplification. Nature, 464, 1334-1337, https://doi.org/10.1038/nature09051.

_ C. Deser, and I. Simmonds, 2012: Local and remote controls on observed Arctic warming. Geophys. Res. Lett., 39, L10709, https://doi.org/10.1029/2012GL051598.

Sejas, S. A., M. Cai, A. Hu, G. A. Meehl, W. Washington, and P. C. Taylor, 2014: On the seasonality of polar warming amplification. J. Climate, 27, 5653-5669, https://doi.org/10.1175/ JCLI-D-13-00658.1.

Serreze, M. C., A. P. Barrett, J. C. Stroeve, D. N. Kindig, and M. M. Holland, 2009: The emergence of surface-based Arctic amplification. Cryosphere, 3, 11-19, https://doi.org/ 10.5194/tc-3-11-2009.

Singh, H. A., P. J. Rasch, and B. E. J. Rose, 2017: Increased ocean heat convergence into the high latitudes with $\mathrm{CO}_{2}$-doubling enhances polar-amplified warming. Geophys. Res. Lett., 44, 10 583-10 591, https://doi.org/10.1002/2017GL074561.

Soden, B. J., I. M. Held, R. Colman, K. M. Shell, J. T. Kiehl, and C. A. Shields, 2008: Quantifying climate feedbacks using radiative kernels. J. Climate, 21, 3504-3520, https://doi.org/ 10.1175/2007JCLI2110.1.
Taylor, P. C., R. G. Ellingson, and M. Cai, 2011a: Seasonal variations of climate feedbacks in the NCAR CCSM3. J. Climate, 24, 3433-3444, https://doi.org/10.1175/2011JCLI3862.1. , and $-2011 \mathrm{~b}$ : Geographical distribution of climate feedbacks in the NCAR CCSM3.0. J. Climate, 24, 2737-2753, https://doi.org/10.1175/2010JCLI3788.1.

—, S. Kato, K.-M. Xu, and M. Cai, 2015: Covariance between Arctic sea ice and clouds within atmospheric state regimes at the satellite footprint level. J. Geophys. Res. Atmos., 120, 12 656-12 678, https://doi.org/10.1002/2015JD023520.

Tiedtke, M., 1993: Representation of clouds in large-scale models. Mon. Wea. Rev., 121, 3040-3061, https://doi.org/10.1175/ 1520-0493(1993)121<3040:ROCILS > 2.0.CO;2.

Tjernström, M., and R. G. Graversen, 2009: The vertical structure of the lower Arctic troposphere analysed from observations and the ERA-40 reanalysis. Quart. J. Roy. Meteor. Soc., 135 , 431-443, https://doi.org/10.1002/qj.380.

Vavrus, S., 2004: The impact of cloud feedbacks on Arctic climate under greenhouse forcing. J. Climate, 17, 603-615, https:// doi.org/10.1175/1520-0442(2004)017<0603:TIOCFO>2.0.CO;2.

- D. Waliser, A. Schweiger, and J. Francis, 2009: Simulations of 20th and 21st century Arctic cloud amount in the global climate models assessed in the IPCC AR4. Climate Dyn., 33, 1099-1115, https://doi.org/10.1007/s00382-008-0475-6.

Wetherald, R. T., and S. Manabe, 1981: Influence of seasonal variation upon the sensitivity of a model climate. J. Geophys. Res., 86, 1194-1204, https://doi.org/10.1029/ JC086iC02p01194.

Winton, M., 2006: Amplified Arctic climate change: What does surface albedo feedback have to do with it? Geophys. Res. Lett., 33, L03701, https://doi.org/10.1029/2005GL025244. 
